\title{
REESCRITURAS EN PROCESOS AUTÓNOMOS DE MANUEL FERNÁNDEZ: O CUANDO LA POESÍA HACE ANÁLISIS SOCIAL ${ }^{1}$
}

\author{
Biviana Hernández Ojeda \\ Universidad de Playa Ancha \\ Valparaíso, Chile \\ biviana.hernandezz@gmail.com \\ Luis Fernando Chueca \\ Pontificia Universidad Católica del Perú \\ Lima, Perú \\ 1chueca@pucp.edu.pe
}

\begin{abstract}
RESUMEN / ABSTRACT
El artículo propone una lectura crítica del poemario Procesos autónomos de Manuel Fernández desde tres líneas de indagación: la noción de autonomía a partir de diversos episodios de la historia peruana y de proyectos de sociedad pensados desde sectores no hegemónicos; las dinámicas de reescritura que operan tanto desde la perspectiva intertextual como de la "académica" del poemario; y las implicancias de este proyecto de escritura en el marco de la poesía peruana e hispanoamericana contemporáneas. Como hipótesis, sostenemos que el libro, además de ser un poemario, con plena legitimidad en el campo literario, ofrece también al lector una propuesta y diseño de una consistente investigación sobre la sociedad peruana.
\end{abstract}

PALABRAS ClaVE: poesía peruana, reescritura, autonomía, poética, política.

1 Este artículo forma parte del Proyecto FONDECYT Iniciación $N^{\circ} 11170009$, "Reescribir o el comienzo de la escritura: poéticas del campo cultural chileno-peruano (19432016)", del cual Biviana Hernández es investigadora responsable y Luis Fernando Chueca investigador asistente. 
REWRITING IN PROCESOS AUTÓNOMOS BY MANUEL FERNÁNDEZ: WHEN POETRY DOES SOCIAL ANALYSIS

The present article proposes a critical lecture of Procesos autónomos, by Manuel Fernández, following three guiding lines: the notion of autonomy in the light of some episodes of Peruvian history and society projects envisaged from nonhegemonic segments, the rewriting dynamics that operate in both the intertextual and the "academic" sides of the book, and the poetic implications that follow from the book as a project that belongs to the contemporary setting of Peruvian and Latin American poetry. Our working hipothesis is that the book, in addition to be a legitimate contribution to the literary field of poetry, offers the reader a proposal and design of a consistent research on Peruvian society.

KEYWORDS: Peruvian poetry, rewriting, autonomy, poetic, political.

Recepción: 08/10/2018

Aprobación: 27/06/2019

\section{PARA COMENZAR}

La práctica de la reescritura no es nueva en poesía. Sin necesidad de ir demasiado lejos, a principios de siglo XX es posible reconocer procedimientos como los de Ezra Pound, por ejemplo, en su "Homenaje a Sexto Propercio", que retoma luego con intensidad la poesía latinoamericana de los años sesenta, de raigambre conversacional. No obstante lo común y frecuente, hay proyectos que llevan estas posibilidades al extremo. Un caso posible de considerar es el del argentino Leónidas Lamborghini, que hace de la reescritura el dispositivo clave de su trabajo poético y de su poética. Otro, indudable, es el de Juan Luis Martínez, cuyas reescrituras, en sus distintas expresiones o modalidades (cita, parodia, readymade, collage) constituyen recursos de producción textual que marcaron el inicio y trayectoria de la estética neovanguardista en la poesía chilena. En la senda martiniana, podría considerarse a Soledad Fariña, que desde su primer poemario en los años ochenta hasta la actualidad ha utilizado sistemáticamente diversos procedimientos de reescritura y apropiación ${ }^{2}$. En el Perú, un caso emblemático es el de Luis Hernández: en sus cuadernos autógrafos retoma y reescribe permanentemente a otros poetas y vuelve sobre sus mismos versos en nuevas versiones. Ejemplos más recientes también en el Perú, de mucho interés por sus particulares inflexiones a partir de tipos

2 Véase, sobre estos procedimientos en Fariña y otros poetas del ochenta en Chile, los artículos de Hernández 2018 y 2019. 
discursivos ajenos a la poesía, son Tratado de arqueología peruana (2005) de Roberto Zariquiey, Procesos autónomos (2016) de Manuel Fernández y Notas para un seminario sobre Foucault de Mario Montalbetti (2018). El poemario de Zariquiey ficcionaliza el recorrido a través del territorio del país ("La costa", "La sierra" y "La selva" son las secciones del libro) por parte de un arqueólogo cuyo propósito, además de escribir el Tratado..., anunciado por el título, parece ser el acercamiento abarcador y a la vez fragmentario al Perú, a fin de comprender la complejidad de los múltiples niveles que lo integran, conocimiento que, espera, podría contribuir a la comprensión y acción en el presente. Notas para un seminario sobre Foucault de Montalbetti, por su parte, presenta nueve poemas que corresponden a ocho sesiones (del mencionado Seminario) y unas "Notas finales": textos que incluyen fragmentos expositivos, apuntes personales vinculados (o no) con los asuntos a tratar, disquisiciones, argumentaciones, preguntas de los participantes y respuestas del profesor-hablante poético del libro, entre otros materiales.

En el caso de Procesos autónomos de Fernández (Lima, 1976) ${ }^{3}$, que abordaremos en estas páginas, se construye un artefacto poético que retoma fragmentos de otros poetas y otros escritos, en particular provenientes de las ciencias sociales y la historiografía, y pone en cuestión algunos cánones de la poesía a través de la escritura de un texto que podría leerse, desde su macroestructura, como un trabajo académico: una monografía acerca de prácticas y discursos autónomos, de carácter político, surgidos desde los sujetos populares o en su representación en el Perú. Se desprenden de esto tres líneas de indagación. La primera corresponde a la problematización de la idea de autonomía en el poemario en relación con el Perú y, a partir de ello, de los proyectos de nación pensados o gestados desde los sectores no hegemónicos. La segunda, a la observación de las dinámicas de reescritura puestas en funcionamiento, tanto las vinculadas con los subtextos del poemario, como con la macroestructura académica del conjunto. La tercera corresponde a las implicancias poéticas de este proyecto de escritura: qué propone respecto de la poesía, cuál es su condición renovadora en el marco de la poesía peruana e hispanoamericana. Aunque estas tres dimensiones están

\footnotetext{
Manuel Fernández es uno de los más importantes poetas peruanos entre los que comenzaron a publicar a inicios del siglo XXI. Procesos autónomos puede verse como la tercera entrega de una trilogía iniciada con Octubre (2006) y continuada con La marcha del polen (2013). Estos tres son los poemarios hasta ahora publicados por Fernández.
} 
imbricadas en el poemario, la revisión se trabajará priorizando secuencialmente cada una de ellas.

\section{PROYECTOS DE AUTONOMÍA EN LA SOCIEDAD PERUANA}

La autonomía referida en el título del poemario puede entenderse, siguiendo al DRAE, como la "condición de quien, para ciertas cosas, no depende de nadie" y, en la dinámica colectiva, vinculada con entidades que gozan de la potestad de "regirse mediante normas y órganos de gobierno propios". Esta perspectiva puede vincularse con la emancipación, término más frecuente en relación con el horizonte utópico de transformación, cuyos alcances y posibilidades se problematizan en el poemario. "Emanciparse" significa "liberarse de cualquier subordinación o dependencia" (DRAE). En efecto, Procesos autónomos aborda representaciones, construcciones y prácticas políticas desde la subalternidad peruana en el camino hacia su autogobierno; procesos en los que la autorrepresentación resulta fundamental. Qué proyectos (logrados o fallidos) han buscado organizar discursos y prácticas de autonomía desde los sectores populares (de modo totalizante o fragmentario), podría ser la pregunta que articula temáticamente el conjunto.

Esta línea de lectura se desarrolla a partir de la estructura del poemario que, como señalamos, retoma la de un trabajo de investigación: una introducción, tres capítulos ("Marco conceptual: la lengua y el espacio de la acción humana", "La construcción de un nuevo lugar de enunciación y sus límites" y "Procesos autónomos"), conclusiones y bibliografía; todo ello precedido por el índice. El libro se abre con un epígrafe del historiador Pablo Macera ${ }^{4}$ que plantea la necesidad de pensar cronologías que escapen de las concepciones evolucionistas de la historia, y que integren, en este sentido, su discontinuidad y lo fragmentario. El epígrafe podría leerse en la clave benjaminiana de cuestionar el tiempo homogéneo y vacío de las sociedades occidentales, tributario de una perspectiva lineal del progreso

4 Pablo Macera (Huacho, Perú, 1929) fue uno de los historiadores peruanos más reconocidos durante las décadas de los setenta y los ochenta del siglo pasado. En los ochenta, a raíz de su visión crítica y pesimista respecto del devenir del Perú, fue considerado muchas veces como una conciencia oracular de la sociedad peruana. 
que desconoce las fisuras que abren y comunican tiempos diversos ${ }^{5}$. Pero el epígrafe sugiere también otras posibilidades. Tomado de Visión histórica del Perú, de Macera, al fragmento citado le sigue ${ }^{6}$ una explicación acerca de por qué no es posible una mirada totalizante de la historia del Perú como proceso nacional articulado. Se trata más bien de varias historias, argumenta Macera, algunas articuladas y otras que corren por separado sin haber "favorecido solidaridades históricas permanentes a partir de los intercambios" (8-11). En relación con las articulaciones señala que, incluso a pesar de la existencia de "unificaciones administrativas (waris, incas)" (7), que instrumentaron, políticamente, patrones comunes de comportamiento colectivo, "[e]n ningún caso, sin embargo, queda supuesta y demostrada la existencia de una nación peruana donde estarían incluidos desde los pueblos neolíticos hasta las sociedades alienadas de los siglos XVI al XX” (7). En el párrafo que continúa a esta cita, para referir los desarrollos al margen de las unificaciones administrativas, Macera utiliza la frase "procesos autónomos", con lo que es posible pensar un sentido distinto al señalado respecto del título del libro de Fernández: no solo apuntaría a revisar la búsqueda de autonomía de los sectores subalternos, sino también a evidenciar la desarticulación de los mismos y, en ese sentido, a la incapacidad de dar forma o llegar a constituir, a pesar de la existencia de algunos esfuerzos en esa dirección, un proyecto nacional pensado desde o para dichos sectores.

Se puede proponer, entonces, que los procesos autónomos sobre los que indaga este poemario están atravesados por las tres dimensiones señaladas: la apuesta emancipatoria, la misma que será revisada en sus posibilidades, alcances y limitaciones; la discontinuidad y lo fragmentario como elementos clave para acercarse a estos diversos procesos, en que determinados aspectos de unos iluminan la comprensión de otros o se recuperan como estímulos para el presente o futuro; y el reconocimiento del fracaso que evidencia, reiteradamente, la incapacidad de construir proyectos de sociedad. Para observar con detalle lo planteado, a continuación revisaremos algunos ejes centrales de cada capítulo de Procesos autónomos.

\footnotetext{
Ver al respecto Lowy 2005.

"A pesar de lo dicho" es el inicio de la cita, con lo que invita implícitamente a la búsqueda de aquello a lo que remite.
} 


\section{A) LAS BASES: LA COLONIALIDAD Y LOS MECANISMOS DEL DESPOJO}

El primer capítulo, "Marco conceptual: la lengua y el espacio de la acción humana", presenta dos poemas. El inicial, "Consideraciones en torno a la formación de una koiné americana alrededor de los primeros años del siglo XVI", al modo de un examen (respondido) de un curso de Dialectología Hispánica, apunta en apariencia a explicar la formación del castellano hispanoamericano: el llamado "período antillano", a raíz de la llegada de los conquistadores a las Antillas, en donde se produjeron los primeros contactos del español con los aborígenes americanos y, producto de ello, las primeras modificaciones de la lengua peninsular. Pero las respuestas a las tres preguntas planteadas -con notas al pie y saltos temporales, como ocurre a lo largo de todo el libro-, se dirigen -a través de una estructura de montaje que desarticula toda pretensión de comprensión lineal-, más que a abordar las tensiones del castellano en contacto con el nuevo mundo, a anticipar-evidenciando su condición de marco conceptual-los nudos que se problematizarán en los siguientes capítulos: la aparición de discursividades que proponen autorrepresentaciones de los sectores subalternos y la lógica de la colonialidad que ha primado en la configuración política, económica y cultural del continente. Se postula también que esta lógica de poder ha impregnado en mayor o menor medida los proyectos de autonomía y es, a la vez, causa de limitaciones en las aproximaciones intelectuales a dichos fenómenos, incluso de las que surgen desde posiciones ajenas a las predominantes en el capitalismo colonializante ("buscamos [...] / explicaciones que lo expliquen todo / desde la racionalidad misma / de / los mecanismos del despojo / -y la relación capital / salario / Es decir / "desde la matriz colonial / La subalternización lingüística / Y epistémica del mundo / (Zavala 2007: 6)”; 22). La categoría de "colonialidad", informa una nota al pie, procede de los trabajos de Aníbal Quijano, y la de "mecanismos del despojo" remite a Las venas abiertas de América Latina (1971) de Eduardo Galeano.

"Ciudad [Algunos apuntes sobre la evolución del espacio en el marco de un proceso de liberalización económica y su impacto en el contrato social]", el segundo poema del "Marco conceptual", propone a Lima como escenario y lugar explícito de enunciación, algo que ocurrirá en casi todos los textos siguientes. El hablante ${ }^{7}$, adscribiéndose a lo señalado en el epígrafe del poeta

\footnotetext{
Es complejo, por la bullente polifonía de los poemas, hablar de "un hablante". Sin embargo, en la mayoría de los casos es posible distinguir una voz principal que parece ser la encargada de organizar el conjunto.
} 
Carlos Oliva ${ }^{8}$, se reconoce como un desheredado de la belleza de la ciudad o, con un símil posterior, "como un viejo Volkswagen desmantelado / solo y abandonado" (24) que recorre -a modo de flâneur en la posmodernidad periférica limeña, en busca de imágenes que develen los sentidos tras las apariencias- espacios en que hay "pandillas de niños miserables", arquitecturas discordantes, crecimientos irregulares y polarización social por la extrema desigualdad. Esto es, una "ciudad sitiada / y su desorden / un espejo hecho trizas a orillas del mar" (25), en que se evidencia que las élites, "incapaces de comprender nada" (25), una y otra vez han huido de los espacios centrales de la ciudad o han demarcado fronteras precisas para formar nuevos reductos en que se sientan a buen recaudo de cualquier amenaza o de las transformaciones de la urbe (como los procesos migratorios, por ejemplo). Los "espacios para indios / espacios para criollos" (25) de la colonia se continúan hoy, por ejemplo, en la distancia (real y simbólica) entre el centro financiero limeño, en el distrito de San Isidro, locus privilegiado de la élite empresarial, y el sector de La Parada, en el distrito de La Victoria, núcleo de llegada de la producción agrícola de todo el país y centro gravitante (que reaparecerá en el último poema del libro) en que se funden comercio formal, informal y delincuencia. La revisión, incrustada de citas del urbanista Wiley Ludeña, aborda los impactos de la modernización neoliberal, que exacerba la polarización social, confrontándose así la Lima moderna y boyante, primermundista en apariencia, y las evidencias más agudas de la precariedad y el despojo, aunque articuladas también al funcionamiento de la dinámica comercial (informal) del país. Cabe recordar, al respecto, que las teorías decoloniales, desde donde surge el concepto de colonialidad, inciden en que en el cotejo entre zonas centrales y periféricas no debe perderse de vista que las posibilidades de las primeras se sostienen en las relaciones de dominación, discriminación y subalternización que se ejercen sobre las segundas.

Además de presentar dispositivos textuales y nociones que seguirán utilizándose, como la de colonialidad, eje central en la aproximación crítica al capitalismo y en particular al capitalismo tardío neoliberal, en que declinan las utopías de tiempos pasados, el capítulo inicial, en tanto marco conceptual,

8 Carlos Oliva (Lima, 1960-1994), fundador del grupo Neón en 1990, trabajó en su único (y póstumo) poemario, Lima o el largo camino de la desesperación (1995), con imágenes que se inscriben en la tradición del malditismo, desarrollando visiones de una urbe en trance de descomposición. 
permite vislumbrar la importancia de los personajes femeninos y cómo se configuran en el poemario, a través de la aparición inicial de "la morenita / que va y viene de la fuente/ [que] sabe sobre esto" (20). "Esto", que parece remitir a todo lo anterior en el poema citado, involucra, en la estructura de montaje del texto, la noción de cultura en trance de modificación, dinámicas lingüísticas, relaciones entre dirigencias políticas y bases sociales, efluvios de la naturaleza y exigencias de "fortalecimiento de las instituciones" (20); es decir, un anticipo, también, de lo que se verá luego en el poemario. Ella sabe de todo eso, "pero se mantiene callada" (20). Al parecer, indiferente y sin agencia, la "morenita" está en realidad atenta a todo y "ensaya / una respuesta // un corpus nuevo / que explique / todos estos cambios" (21).

\section{B) Discursos AUTÓNOMOS: POSIBILIDADES, ALCANCES Y LÍMITES}

El segundo capítulo, "La construcción de un nuevo lugar de enunciación y sus límites", entra de lleno en un aspecto central de la investigación social que emprende Procesos autónomos: cómo se configura y desde dónde ese magma de voces que busca representar, en el doble sentido de la palabra, los "procesos autónomos" en el Perú. El primero de los cuatro poemas de la sección, "Fuentes para el estudio de la lírica popular limeña", al abordar el discurso de las letras de la música popular limeña, problematiza una de las ideas centrales respecto de la "poesía peruana" con la que la tradición crítica suele operar. Esta, como se conoce, no solo prioriza la producción limeña o que ha circulado en o desde Lima, sino que considera habitualmente solo la producción letrada culta (Cornejo Polar). El poema, al hablar de "lírica popular limeña", impugna implícitamente la centralidad de la escritura en la poesía ${ }^{9}$ y destaca la existencia de una tradición poética oral y popular que representa claramente el intento "de construir una historia y un discurso propios, bajo estructuras y formas distintas a aquellas en las que se articulaba el discurso oficial" (35), como se refuerza en las notas al pie que remiten a un ensayo de Fred Rohner (2007) que da título al poema ${ }^{10}$ y varias otras citas al interior de este.

9 Pues si bien los textos populares citados en este y los siguientes poemas de la sección son referidos a partir de su fuente escrita, se trata de textos que se conocen fundamentalmente por su circulación oral-musical.

10 Buena parte de los títulos de los poemas o de secciones en estos han sido tomados de otros textos, lo que no solamente evidencia aspectos de la dimensión reescritural del poemario, sino que invita a establecer vínculos de interesantes consecuencias para su lectura. 
Pero el texto apunta, en paralelo, que los discursos autónomos que se expresan en esta práctica textual no están exentos de limitaciones y contradicciones, en gran medida porque no han dejado de articularse con la lógica colonializante de las élites. Al respecto, alude Fernández, quizás en diálogo con un motivo muy presente en la "poesía culta" (Moro, Delgado, Rose, por ejemplo), al influjo adormecedor de la conciencia crítica propio de la ciudad de Lima, lo que se refuerza con palabras como "adormece", "lentamente", "suavemente", "rumor", "caricia" o "mansa" (33-34). Se muestra, en este sentido, que la poesía popular limeña (la registrada en los fragmentos citados), si bien autorrepresenta otras miradas y sentires, que dan cuenta de entusiasmos, vocación celebratoria y vitalidad, evidencia a la vez que comparte la visión autocomplaciente y excluyente característica de la Lima tradicional, proyectando la autoimagen de una ciudad armónica, criolla, no conflictiva y bella, cuyos habitantes (y no solo los de las élites) viven sin reconocer las complejidades de la estructura social ni los enfrentamientos patentes o latentes que se desprenden de ella ${ }^{11}$. El poema muestra, como escena alterna a las ofrecidas por las canciones citadas, la urgencia de las demandas cotidianas, agravada al llegar el neoliberalismo de los años noventa, que obstruye el desarrollo de una conciencia crítica más activa en el marco de la obligación de sobrevivir: un "vaciamiento simbólico", en términos de William Rowe. Sigue operando así, de modo invisible pero efectivo, la silenciosa dinámica ideológica de reproducción de los valores sostenidos en los discursos de las élites, en sus formas de organizarse y en los conceptos "pensables" que proponen.

A partir de la crítica de esta visión idealizada y excluyente, el hablante del poema concluye "que es imposible derribar los cimientos que sostienen el

11 Así ocurre con "El jilguero qué bien canta", grabada por Montes y Manrique en los años treinta o con el vals "Acuarela criolla" de Manuel Raygada ("Lima está de fiesta, / la canción criolla / se viste de gala, las guapas limeñas / lucen su belleza / y gracia sin par. / Las cuerdas de las guitarras trinan / los criollos corazones vibran / a los alegres sones / de la canción popular... / tan tan"), que se repite tres veces en el poema casi a modo de música de fondo, imprimiendo en el recorrido urbano (contemporáneo) un tinte de celebración que no reconoce la conflictividad de, por ejemplo, las exclusiones a las que ha sido sometido lo andino (como sostiene Portocarrero en la cita que se usa de intertexto: "la identidad criolla se fundamenta en el repudio de lo indígena, considerado como lo abyecto, como aquello que se debe rechazar para ser digno y valioso"; 37), o la que emerge de los procesos insuficientes de modernización. Cabe, por supuesto, la pregunta sobre otras producciones en este ámbito para tener miradas alternativas a la ofrecida. 
edificio de nuestros estereotipos" (37). Pero la evaluación es aún más compleja, pues a la par que cuestiona el estatuto de estas producciones artísticas, sugiere que "La educación (...) concebida como disciplinamiento" [...] (Portocarrero 2001)" (36) atañe no solo a los sectores sociales "acríticos", sino también a las propias dinámicas de la crítica, sustentada muchas veces en modelos eurocéntricos y lógicas colonializantes. El poema no ofrece soluciones ni conclusiones cerradas al respecto; más bien, permite imaginar que esto puede atribuirse incluso a una mirada como la que articula Procesos autónomos, o a los comentarios sobre el poemario, aun a riesgo de generar un círculo interminable de desánimo o frustración.

El siguiente poema, "Crónica de impronta oral en la conquista del Perú: análisis del discurso desde el centro mismo de la estructura contemporánea de los mecanismos del despojo", el más complejo y extenso de la sección, revisa estas tensiones a partir del caso del cronista español Alonso Borregán. El texto reescribe la historia de Borregán, situado por el historiador Raúl Porras Barrenechea, tal como se cita en el poema, "entre los cronistas [...], en última línea, al lado y después de Huamán Poma" (44). Llegado al Perú en los primeros años de entrada de los españoles -aunque no hay certeza de su presencia en el evento fundacional de Cajamarca, referido en su Crónica de la Conquista del Perú (1565)-, Borregán redactó, además de su crónica, una serie de peticiones al rey de España en que solicitaba la revisión de su caso, pues se sentía despojado de los beneficios, tierras e incluso indígenas: ("En guarda de mi Derecho así tocante / a los yndios como en otras cosas / a mi perteneczientes", 44) que a su juicio le correspondían. En varias partes del poema ("[Las peticiones del cronista]", "[En guarda de mi Derecho asi tocante...]" y "[La entrevista de Mala]"), el hablante cede la voz a Borregán (a través de citas de su crónica) para que hable de "los despojos y maldades que ha sufrido", a la vez que yuxtapone tiempos y espacios diversos dentro de su relato: el presente inmediato del hablante del poema, que corresponde al tiempo contemporáneo; los inicios del gobierno de Velasco, momento sugerido por la mención del 3 de octubre como fecha emblemática ${ }^{12}$, y el pasado colonial, a partir de las citas de la crónica y los petitorios de Borregán. Pero estos últimos también se desplazan hacia el tiempo contemporáneo y 
colocan al cronista ante la Coordinadora Nacional de DDHH ${ }^{13}$ en Lima -de modo análogo a como se presentara en el siglo XVI, ante el Consejo de Indias-, en donde lo vemos luego abordando "su carro / un reluciente volkswagen blanco" (46), que no puede avanzar por las manifestaciones y protestas de los estudiantes enfrentados a la policía, motivo constante del poema, que anticipa, además, uno de los nudos del tercer capítulo.

Retomando las contradicciones exploradas en el poema anterior, este texto equipara a los encargados de evaluar los reclamos de Borregán, antes y hoy, mencionando a los del presente como "los mismos funcionarios de la colonialidad del poder" (41). Advierte, al mismo tiempo, que Borregán "ha hablado / desde el centro mismo / de la racionalidad específica del poder / colonial / eurocentrista / es decir / -también / desde la estructura contemporánea / de los mecanismos del despojo" (42). El nudo que configuran estas menciones expresa cabalmente algunos de los planteamientos fundamentales del poema y de todo el poemario: se propone que quienes ejecutan o defienden "los mecanismos del despojo", como Borregán reclamando sus derechos de propiedad sobre los indígenas supuestamente adquiridos por su condición de "descobridor y conquistador" (41), pueden ser objeto también de esos mecanismos semejantes ("son ya tantas las persecuciones y injusticias y agrauios / que se me an ehcho", 41) por parte de otros con mayor poder. Esto parece ocurrir con Borrgeán por su baja condición social, reflejada en su escritura de "impronta oral" (39). Pero cuando el poema informa que "los jueces se impacientan" por la "poca destreza con las palabras" y se ríen "de su lengua bárbara", la alusión no implica solo a los encargados coloniales de evaluar sus reclamos, sino también a los representantes de "la Coordinadora Nacional / de DDHH”, que implícitamente suscriben los juicios de Porras, uno de los historiadores más respetados del siglo XX peruano. Se evidencian, así, como contraparte del planteamiento anterior, las paradójicas dependencias frente a las lógicas de la colonialidad por parte de quienes debieran estar más lejos de ellas, trazándose de este modo un nuevo hilo hacia el tercer capítulo.

La superposición de tiempos y acontecimientos de la historia peruana también es clave para el reconocimiento de diálogos y continuidades fundamentales

13 La CNDDHH, constituida en 1985, fue la primera institución en América Latina que articuló a los organismos de derechos humanos de un país. Su papel en la lucha contra las violaciones de derechos humanos en el marco del Conflicto Armado Interno peruano fue fundamental. 
entre los diversos procesos autónomos de la sociedad peruana (y en sus límites, como anuncia el título del capítulo) en los dos sentidos propuestos al comienzo de este trabajo: emancipación y desarticulación. Al inicio del poema leemos: "Pensar / en Alonso Borregán / hoy jueves / 3 de octubre // cuando las tensiones crecen sobre el césped de la patria // y las protestas se adormecen / al abrigo de las pancartas // también / hay estudiantes que abandonan las aulas / y entonan el himno // como un viejo recurso // resueltos / ocupan con entusiasmo las plazas / sin saber / que a cuatrocientos treinta y seis años de distancia / los esperan los tanques / y escuadrones antidisturbios" (40). La fecha inicial del 3 de octubre parece colocar el presente de la enunciación, en primera instancia, en 1968, pues ese fue el día del golpe de Estado de Velasco Alvarado, general del ejército peruano, a Fernando Belaúnde, que dio inicio al autodenominado "Gobierno Revolucionario de las Fuerzas Armadas". Este régimen, aunque autoritario como toda dictadura, tuvo en su Primera Fase (1968-1975), la encabezada por Velasco, un claro signo progresista y antioligárquico que enarboló un proyecto nacional, quizá el único en toda la historia colonial y republicana del Perú que contempló simbólica y efectivamente mecanismos de incorporación de los indígenas a la vida nacional en la perspectiva de su emancipación. La posibilidad de fechar el 3 de octubre en 1968 se refuerza en tanto los "cuatrocientos treinta y seis años de distancia" mencionados conducen, retrocediendo en el tiempo, a otro hito de la historia peruana: 1532, año de la captura de Atahualpa en Cajamarca, escena fundacional de la conquista del Perú (ver Cornejo Polar 1994), aludida a su vez en la frase "[De Cajamarca al sitio del Jr. Cuzco]", que es el título de una de las partes del poema que retoma el de una de las secciones de la crónica de Borregán con el añadido de "Jr.", que parece desplazar la escena construida por el poema hacia Lima ${ }^{14}$.

A partir de la posibilidad de reconocer 1968 como el año aludido, la mención de los tanques y las pancartas podría remitir a protestas frente al golpe, hecho que daría cuenta de las contradicciones generadas por el proceso, apoyado por muchos sectores frente al descontento del gobierno anterior (entreguismo frente al capital extranjero, crisis económica, incapacidad para la solución de los problemas sociales, freno de los sectores oligárquicos desde

14 Todos los títulos del poema retoman títulos de secciones de la crónica o de los petitorios de Borregán. El título remite también al "Sitio del Cuzco", momento fundamental en la resistencia de Manco Inca (1536-1537) frente a la conquista española. 
el parlamento a las reformas necesarias, etc.), pero también resistido tanto desde los sectores oligárquicos como desde buena parte de la izquierda, e inicialmente además por muchos que creyeron que sería un golpe militar más en la historia del Perú. El "hoy" del inicio del poema, sin embargo, en conjunción con las otras secciones, hace pensar en otros posibles presentes de enunciación, más recientes. En "[Cosas de indios /final]", por ejemplo, en que se retoma el verso "a cuatrocientos treinta y seis años de distancia", se sugiere que la escena corresponde a la actualidad por medio de la frase "AQUÍ DISCUTIENDO CON UN GUARDIA” (47) (como leyenda que acompaña una fotografía), citada por el nosotros que enuncia la sección al explicar la celebración con cervezas en un bar del Centro de Lima luego de finalizar una protesta, pues, como es conocido, la expresión "Aquí + gerundio..." es de uso frecuente en las redes sociales al compartir fotografías que dan cuenta del anecdotario del emisor. Parece esbozarse con esto una crítica a la aparente banalización que quita densidad al enfrentamiento sostenido, aunque también podría aducirse un reconocimiento a la celebración vital, juvenil, de lo ocurrido, que no elimina su importancia, aunque revele quizá algunas de sus contradicciones ${ }^{15}$. La escena fundacional de Cajamarca, en tanto inicio del proceso de conquista (y entonces inicio de la colonialidad en el Perú), también permite reconocer otras continuidades, sobre todo a partir del paralelo posible entre las resistencias que generó (la del sitio del Cuzco por parte de Manco Inca en 1536 y 1537, por ejemplo, finalmente fracasada) y las que se reinterpretan, una y otra vez, en momentos contemporáneos de la historia nacional, como las de los estudiantes del poema.

El poema termina con "[Cosas de indios / final]", que presenta la celebración, por parte de los jóvenes, de sus protestas y enfrentamientos con la policía, en un bar en donde vuelve a aparecer "la morenita" (mujer y afrodescendiente) en un nuevo apunte sobre la lógica patriarcal que actúa junto a la colonialidad del poder. El lugar del sujeto femenino también se problematiza en los dos siguientes poemas. En "Período formativo local", el hablante, mediante referencias autobiográficas al distrito limeño de Breña (locus privilegiado en la obra de Fernández) y al nombre de Manuel, por un lado; a letras de boleros y otras composiciones del repertorio romántico popular latinoamericano, junto a versos de poetas peruanos, por otro, tensiona

15 Como las contradicciones en la música popular no cancelan la importancia de su propósito de articular un discurso propio. 
las relaciones entre amor, deseo, clase, etnia y estructuras sociales. Y en "Santa", el último poema del capítulo, aborda la figura de Santa Rosa de Lima, intersecando citas del libro homónimo de José Antonio del Busto con versos de Noches de adrenalina (1981) de Carmen Ollé. El poema muestra a la santa como una mujer rebelde, consciente y segura de su desviación de la norma patriarcal: "se rapó el cabello / que era rubio bien entintado / y desoyó los pedidos de su madre de casarse /porque prefería pasarse la tarde / quieta / y sola / mirando / desde la ventana / el suave acoplamiento de las vacas / mientras pensaba: / "la crema Nivea sirve para que la palabra pene se sumerja / tranquilamente en la palabra ano" (Ollé 2014: 61)" (56). La yuxtaposición de citas contrasta la visión rebelde de los versos de Ollé - no referidos a Santa Rosa, sino a la condición de mujer-poeta (peruana y tercermundista) en la sociedad actual- con la mirada documental del historiador que recrea la vida de la santa enfatizando su dimensión divina ("El objetivo supremo para Rosa siempre fue Dios. // Todo lo demás era efímero y superfluo"; 58). El contraste genera una lectura de Santa Rosa de Lima como una mujer que trasgredió las convenciones establecidas en torno a los roles de género, a diferencia del personaje de la "morenita" que, vista y valorada por los ojos del hablante, aparece aquí como una muchacha más bien ingenua y superficial: "la morenita [...] se lanza a la piscina / con su bikini blanco de bolitas [...] / y tiene vellos pintados de rubio / y se luce orgullosa entre los borrachos / que de noche la celebran" (49).

\section{C) HACIA LA AUTONOMÍA EN LA ACCIÓN POLÍTICA: PROYECTO Y FRACASO}

La tercera parte de Procesos autónomos es la que le da el título al libro y presenta tres poemas que abordan de manera central -a diferencia del capítulo anterior que lo hacía desde el discurso y problematizando el lugar de enunciación- proyectos de autonomía desde la perspectiva de la acción política directa: el gobierno militar progresista de Velasco Alvarado, el papel de la izquierda durante el período de violencia política de los años ochenta y el gobierno municipal en Lima de la coalición progresista Fuerza Social entre 2011 y 2014. En los tres poemas se exploran las expectativas que despertaron y sus logros, así como sus límites y contradicciones, además de los fracasos que representaron desde la perspectiva de la relación entre discursos y prácticas.

En el primer poema, "[El discurso como interacción social]”, el hablante colectivo, "nosotros", enuncia la épica del sujeto social al que representa (popular, progresista y organizado), envuelto en la vorágine del proceso de 
transformación social conducido por el gobierno de Velasco (1968-1975) ${ }^{16}$. El hablante celebra participar en esta dinámica que conduce hacia "el desmembramiento de la burguesía / la destrucción de sus privilegios" (61), así como - citando el "Discurso de la Nación" de Velasco del 28 de julio de 1969- el papel de su conductor: “"una nación entera y su Fuerza Armada emprendieron / el rumbo de su liberación definitiva / sentaron las bases de su genuino desarrollo / doblegaron / el poder de una oligarquía egoísta y colonial / recuperaron / su auténtica soberanía (...)'(Velasco 1969)" (61). El proceso en curso es representado como un enfrentamiento contra la herencia colonial (Cotler) del saber/poder que ha predominado en la historia del Perú, a través de modificaciones en las estructuras de propiedad, empoderamiento de las organizaciones populares, redistribución de beneficios y proyectos de educación crítica orientados a la toma de conciencia de los sectores subalternos, que parecen poder concretar así las expectativas de liberación y genuino desarrollo de la nación peruana frente al poder del "colonialismo / el neocolonialismo / la intromisión del capital foráneo y la reacción” (62). Los cambios en marcha - expresados en vibrantes versos que relevan además las emociones asociadas a aquellos (alegría, deseo, seguridad, insolencia, rabia)- alteran la percepción del tiempo que parece acelerarse a la par que la sociedad se transforma: "ya no hay vuelta atrás // y las manecillas de nuestros viejos relojes giran / enloquecidas" (62). La percepción del proceso como acontecimiento, es decir, según señala Žižek, como "algo traumático, perturbador, que parece suceder de repente y que interrumpe el curso normal de las cosas; algo que surge aparentemente de la nada, sin causas discernibles, una apariencia que no tiene como base nada sólido" (2015: 16), se refuerza con el uso del presente verbal y la alusión a las construcciones "donde palpita el cemento / músculos y concreto" (63), que el régimen opone a las "viejas vigas [que] se tensan se quiebran / ni oponen resistencia" (62).

No obstante, desde el inicio del poema, aunque primero sutilmente, se asoman elementos que fisuran la seguridad épica. Los versos que anteceden al discurso de Velasco anuncian: "al grito de nuevas consignas / los obreros trabajan / y las contradicciones se superan / la historia nos sonríe /... / LA

16 El gobierno implementó una política de nacionalizaciones (estatización del petróleo y de importantes empresas mineras) y legislaciones procampesinas (reforma agraria, reconocimiento de la diversidad cultural, oficialización del quechua). En paralelo se dio amplia difusión a un discurso nacionalista que, por ejemplo, propuso la figura rebelde de Túpac Amaru II (1738-1781) como un ícono oficial del gobierno. 
NACIÓN SE CONSTRUYE / por decreto supremo / bajo estos bellos principios" (61). Y a continuación se lee el fragmento ya citado de Velasco. En la secuencia, se puede percibir un contraste entre las enfáticas mayúsculas y el resto del fragmento. Aquellas parecen expresar la fuerza del proceso: la nación en irreversible transformación. Sin embargo, las minúsculas que siguen -que dan paso a los "bellos principios" del régimen y podrían entonces pasar inadvertidas- señalan que la construcción nacional se da "por decreto supremo". Aunque podría implicarse que los cambios se sellan con nuevas estructuras legales, como efectivamente ocurrió, también se sugiere el sinsabor del hablante frente a un proceso que, si bien movilizó contundentes entusiasmos y energía social, adoleció de una evidente falta de solidez, precisamente, por ser una transformación "por decreto": una edificación discursiva y una práctica controladas desde el Estado, cuando se requería de mayor autonomía por parte de los actores sociales. En este mismo sentido se puede leer la aceptación de un esquema pedagógico autoritario ("y las instrucciones que nos dieron fueron claras"; 64) que atenta contra la idea de una conciencia y acción autónomas en los sujetos involucrados en los cambios. Al final, luego de la expresión de desconfianza respecto de las expectativas generadas ("como si fuera posible / ¡ es que era la fuerza! / nuestro deseo / en solo un par de décadas / cambiarlo todo"; 64), el hablante declara abiertamente lo fallido de este proceso autónomo y contrasta este fracaso con la fuerza épica que expresaba los entusiasmos desatados por la modernización integradora: "engranajes de una maquinaria que combustiona sobre sí misma / capaz de poner en evidencia las contradicciones sociales / de encender la pradera / y proclamar una revolución como una condición necesaria dentro de nuestro / proceso histórico / nacional // una estructura perfecta / dijeron / (una estructura sin bases reales / que se desploma / estrepitosamente).” (65).

"[Elementos excluyentes de la acción humana sobre la dimensión histórica]", el segundo poema, se organiza estructuralmente a partir de un verso que, al modificarse, evidencia cambios en la mirada enunciadora: un "nosotros" que corresponde a activistas de organizaciones de izquierda, y en particular a defensores de derechos humanos, en el contexto de la violencia política de la segunda mitad de los años ochenta, durante el primer gobierno de Alan García (1985-1990). El verso que abre el poema es "DESPUÉS DE LAS BOMBAS VINIERON LOS OBREROS" (66), que se transforma en "Después de las bombas vinieron los bomberos" (68) y finalmente en "Después de las bombas vinieron los técnicos" (69). La primera de estas frases permite abordar la violencia política estatal, como la evidenciada 
en las masacres de Accomarca y Cayara ${ }^{17}$, "para denunciar / la existencia / de un aparato genocida subvencionado paraestatal / [...] / para denunciar en las calles la desaparición forzada" (66-7). El hablante colectivo insiste con valentía en los reclamos a pesar de decepciones o reveses: "buscamos / entre los heridos / caras conocidas / visitamos / comisarías hospitales cuarteles centros parroquiales / todo inútil // pero seguimos / volanteando / escribiendo panfletos y visitando sindicatos / llenando los muros de las universidades con nuestras urgentes demandas // hasta quedar exhaustos / y dormirnos / abrazados a una ideología que a estas alturas se ha quedado vacía" (67). Al final de la cita se muestra el nudo de esta escena inicial y eje de la preocupación de todo el poema: ¿qué sucede ideológicamente con la izquierda en este contexto? Quienes denuncian la violencia del Estado, activistas y miembros de organizaciones sociales y políticas, calificados como "obreros" para remarcar la ideología correspondiente a su posición de clase, persisten seguros de caminar hacia un horizonte -aún vigente en esos años- de transformación radical de la sociedad. Como se anuncia en el epígrafe de Nelson Manrique, esto les demanda, además de la denuncia y la militancia, replantearse el lugar de la violencia en la lucha política, más aún en un escenario en el que dos actores habían asumido ese camino: Sendero Luminoso y MRTA. Para la izquierda legal, cuyo discurso incluía aún por esos años el ideologema de la revolución y la visión de "“[1]a democracia [como] una trinchera más para denunciar al sistema burgués y no como sistema político para resolver conflictos' (Gonzales 1999: 23)" (67), la pregunta resultaba, no solo inevitable, sino también urgente.

Desde esta perspectiva, se entienden mejor los distintos momentos del poema y las variaciones en el verso citado ("Después de las bombas..."). La mención de los "bomberos", cuyo intertexto es el conocido refrán sobre el paso del joven incendiario al adulto bombero, alude a los cambios ideológicos y programáticos producidos, que se abordan en el poema en contrapunto con citas de Señales sin respuesta (1999), libro de Osmar Gonzales que estudia las discusiones en el pensamiento socialista peruano de la época a partir del colectivo Los zorros ${ }^{18}$. Con "los bomberos" se sugiere la renuncia, por parte del

17 Se trata de incursiones del Ejército en comunidades ayacuchanas en que fueron asesinados 62 y 35 campesinos, respectivamente. La de Accomarca ocurrió en 1985 y la de Cayara en 1988.

18 Grupo intelectual y político que constituyó uno de los sectores del Partido Unificado Mariateguista. El colectivo fundó la revista El zorro de abajo (1985-1987), que promovió un 
nosotros enunciante, a la acción política directa por la transformación radical de la sociedad, para asumir, a través de oenegés, tareas de intermediación para el desarrollo y la consolidación de la democracia representativa, así como de elaboración de narrativas respecto del proceso de violencia. El poema expone el adelgazamiento ideológico y el inicio de la frivolidad del dinero y las comodidades frente a los cuales el "nosotros" confiesa, autocrítico y desencantado: "conseguimos financiamiento / estrechamos lazos / con la cooperación internacional / y nos enamoramos del vino blanco/ los hoteles caros / sus mujeres/ acariciamos en la cama la fama que no nos dio nunca la lucha armada" (69).

El tercer momento corresponde a la llegada de los "técnicos". Ya no se trata de "los obreros" (los incendiarios del refrán que agitaban la consigna de la lucha revolucionaria) convertidos en "bomberos", amantes de la recién descubierta comodidad de su nueva posición, sino de los que, desde la orilla del neoliberalismo galopante y pronto imperante, proponen el capitalismo popular, la lógica del éxito y el emprendedurismo, "que supo calar mejor entre los sectores populares de mediados y fines de los ochenta que el discurso socialista" (69), según una nueva cita de Gonzales. En esta misma se señala, sobre un famoso libro de Hernando de Soto que emblematiza ese nuevo paradigma, que "[1] os intelectuales socialistas discutieron con El otro sendero sobre todo desde un plano académico, sin percatarse de que era un texto fundamentalmente político" (69). El hablante, que en los dos versos finales del poema no deja ya evidencias del "nosotros" en que se incluía, concluye, en un nuevo diagnóstico del fracaso de los procesos autónomos desde la izquierda: "y no hubo necesidad / de recomponer el discurso" (69). El poema esboza así la inviabilidad de la alternativa colectivo-revolucionaria. Después del fracaso y la renuncia a la convicción en la transformación social vía la lucha de clases, en el contexto del "fin de las ideologías" y la "caída de las utopías", el modelo económico neoliberal parece quedar como único camino imaginable.

Finalmente, el tercer proyecto en la perspectiva de la autonomía de los sectores populares que revisa el libro es el que corresponde al gobierno municipal progresista de Fuerza Social, con Susana Villarán como alcaldesa. Esto ocurre en el último poema del libro, "[Del triángulo sin base a la

importante debate sobre socialismo, democracia representativa y violencia en el Perú de los ochenta. 
desaparición del vértice]", cuyo título es una frase que encabeza una sección del artículo de Carlos Meléndez citado en la bibliografía ("Mediaciones y conflictos: las transformaciones de la intermediación política y los estallidos de violencia en el Perú actual"), que aborda los nuevos tipos de mediación, por parte de operadores políticos, entre el Estado y los sectores populares, en estos tiempos de renuncias utópicas e ideologías adelgazadas. Partiendo del concepto de "triángulo sin base" que utilizó Julio Cotler a fines de los años sesenta para explicar la relación entre las masas campesinas, los gamonales y los poderes dominantes, Meléndez propone que la intermediación actual entre los sectores populares y el Estado, sobre todo a partir del quiebre institucional provocado por el fujimorismo y la consolidación neoliberal, son representaciones políticas endebles y pasajeras, alejadas de las convicciones ideológicas y ajenas de las reivindicaciones históricas o estructurales de dichos sectores, que se organizan ahora en torno a intereses más efímeros y muchas veces oportunistas.

En este escenario, que ya se anunciaba en el poema anterior, parece reactivarse, sin embargo, una posibilidad emancipatoria. Así, el texto se inicia con una cita del ideario del proyecto político en cuestión: "Partido Descentralista Fuerza Social propone adoptar una nueva estrategia de inserción en el contexto internacional, que abarque múltiples dimensiones [...], y cuyo objetivo central sea ampliar las posibilidades colectivas e individuales de todos los peruanos y peruanas" (70). El programa apunta a construir una "izquierda moderna", inserta en el contexto internacional, sin abandonar su compromiso de "desterrar de nuestro país la pobreza, el agobiante centralismo [...], las políticas económicas que generan la desigualdad en la que vive la inmensa mayoría de nuestro pueblo" (70). Pero su "racionalidad nueva" (70), que admite la centralidad del mercado (aunque "al servicio de toda la sociedad", 70), "impone / estructuras modernas" (70). Como muestra de esto, y de que "todas las ideologías cambian / y se comen a sus hijos" (71), el hablante (ya casi totalmente desgajado del "nosotros" enunciante de los poemas previos) examina la decisión del gobierno municipal de dotar de un nuevo Gran Mercado Mayorista, propio de una capital que se pretende del siglo XXI, para cuyo funcionamiento cabal debía desalojar el emblemático mercado de La Parada, en el distrito de La Victoria, a lo que un importante porcentaje de comerciantes y trabajadores se negaba.

Hay dos nudos en este desencuentro: uno, a partir de la pista brindada por el título del poema y el texto de Meléndez, es la relación entre economía informal, fragmentación en la organización social y ausencia de dirigencias 
que representen los intereses populares coherente y consistentemente. El otro, más presente en el cuerpo del poema, apunta a la incapacidad del Estado, en este caso el gobierno progresista de Lima, de reconocer las demandas y necesidades afectadas por su decisión, con lo que este proyecto que "mira al futuro" termina desconociendo a "las masas" y actuando casi desde la misma lógica excluyente que declara querer frenar o reparar, pues se guía con una "racionalidad lineal / discreta" que "llega y ordena el mundo de otra manera / un diseño / donde todo quede muy bien explicado" (71). Este diseño, insinúa el poema, se corresponde con el que ocupa, en el discurso público, la lógica del mercado. Desde esa doble mirada, el poema pone nuevamente en escena el fracaso de un proyecto de autonomía vinculado con los sectores subalternos. Fernández reproduce las explicaciones sobre el papel del mercado en la visión de Fuerza Social para preguntar, con ironía y pesar: "¿[...] es este el discurso? / una ideología que se vacía” (71) y luego "¿Y ESA IZQUIERDA CON LA QUE CRECIMOS DÓNDE HA DE ESTAR?” (72). Las preguntas sintetizan los ejes centrales de su balance sobre la izquierda moderna y renovada "que va dejando cosas de lado / sin compromiso / sin individuos a quienes representar" (72).

Con el desalojo de La Parada, Procesos autónomos parece diagnosticar el fracaso definitivo de los proyectos que en distintos momentos de la historia reciente del Perú pretendieron contribuir a la ansiada y nunca cumplida modernidad y emancipación desde la perspectiva de los sectores populares. Evidencia también las desarticulaciones y desencuentros que contribuyeron a este derrotero. La ideología de la "izquierda moderna", adelgazada y hasta impregnada por lógicas a las que declara enfrentarse, corona este fracaso al dar pie al enfrentamiento de la policía, convocada por el municipio, con los grupos subalternos, durante los hechos de La Parada, que provocaron cuatro muertos y muchos heridos. Al respecto, una nueva cita del libro de Gonzales refuerza la mirada de Procesos autónomos sobre estos acontecimientos: "Salta a la vista que no son los intereses del Perú, sino los del capital internacional y los grandes monopolios los que mandan en el país cuando para 'salvar' la economía 'nacional' hay que agredir empobreciendo aún más a las clases trabajadoras" (72). La cita es reveladora, pues se trata de un texto de 1999 referido a la acción de las élites económicas y políticas del país, el cual es utilizado para interpretar una decisión de un gobierno municipal autodefinido "de izquierda" en el año 2012, y así, además, trazar una continuidad entre los procesos de los poemas de la sección. Con este episodio, sintomáticamente representado en la portada del libro a través de una fotografía trabajada con 
recursos visuales que recuerdan al "pop achorado" (Buntinx 1983) de los afiches que el artista visual Jesús Ruiz Durand realizó para la difusión de los proyectos sociales del velasquismo ${ }^{19}$, el hablante, al final del libro, ya no se representa como sujeto colectivo ("nosotros"), sino como un testigo anónimo que, tajante, resume y evalúa los hechos en tercera persona: "se concreta / el final de una epopeya / la completa renuncia de la izquierda a representar al pueblo / su incapacidad / todo su fracaso" (73).

\section{PROCEDIMIENTOS DE REESCRITURA (O CUANDO LA POESÍA HACE ANÁLISIS SOCIAL)}

El recorrido anterior permite corroborar lo sugerido al inicio: que Procesos autónomos es un libro cuya autoexigente condición textual como poesía diseña una investigación acerca del Perú. La revisión ha ofrecido, a la vez, una mirada a la organización estructural del poemario y a sus procedimientos textuales. Sobre lo primero, es claro que el libro, a partir de su estructura "académica" (introducción, marco conceptual, capítulos de desarrollo, conclusiones y bibliografía), se propone, en efecto, como una indagación sobre proyectos de autonomía en el país en ámbitos diversos, como las reconfiguraciones del lenguaje en contextos interculturales, las autorrepresentaciones de los sectores subalternos, las contradicciones en dichos proyectos por no haber desterrado las lógicas colonializantes y la atención particular a algunos hitos fundamentales en el Perú de la segunda mitad del siglo XX. Al respecto, Fernández, en la introducción del libro "confiesa" que su escritura representa un intento tanto de acercamiento como de distancia frente a "lo académico". En esta dinámica (paradójica, como mucho de lo rastreado por el poemario), la confianza inicial deviene en decepción por "lo lejos que puede encontrarse

19 El concepto de "pop achorado", acuñado por Ruiz Durand en relación con los mencionados afiches, lo difundió por primera vez el crítico de arte Gustavo Buntinx en un artículo de 1983. Una explicación reciente del término la brinda el propio Ruiz Durand en una entrevista con Miguel Sánchez: “Así como estábamos hablando ahora se me ocurrió decir esto porque no había otra forma en ese momento. Cómo haces que un cholo, un indio, un campesino, aparezca como tal en primer plano con orgullo, con conchudez y con una presencia digna. Pop es pop, Lichtenstein si quieres. Achorado porque el achore es la insolencia, es el cholo respondón, no es el cholo sumiso. Acholado no tanto sino más bien achorado" (Sánchez 2016: 117). 
la academia peruana de la sociedad peruana" (15), debido a sus modelos acartonados e insuficientes "que cada vez se distancian más de la realidad" (15), como se refuerza luego en varios pasajes.

Procesos autónomos representa, en este sentido, un esfuerzo por evitar esos escollos de lo académico y evidencia la importancia de sus procedimientos textuales (el segundo aspecto mencionado) en dicha perspectiva: el uso sistemático de citas, refraseos y reescrituras que dan cuenta de la autoconciencia polifónica en la escritura en la medida en que esta va constatando, en cada ejercicio reescritural, que toda habla está hecha de otras hablas, sin posibilidad de creación o enunciación ex nihilo. Cada texto configura un montaje en que las partes puestas en relación cobran nuevas resonancias en el doble flanco de lo estético y lo político (Didi Huberman), pues el poemario, no solo desde las citas y reescrituras, sino también en su uso de espacios, blancos, cortes versales, cursivas, mayúsculas, etc., enriquece sus posibilidades de significación y acercamiento al objeto de estudio al que se aproxima. Se trata, pues, de un proyecto de investigación, pero de uno que -y así logra sortear los lastres criticados- se inscribe también, y fundamentalmente, en los territorios de la poesía. Desde esta condición, el trabajo de montaje de fragmentos que provienen de las ciencias sociales, de voces de actores políticos y sujetos sociales específicos (Borregán, por ejemplo) y de producciones poéticas y musicales, recusa la visión lineal de la historia (el tiempo vacío y homogéneo del "progreso") y potencia, a partir de fricciones (Masiello) entre voces, tonalidades, texturas y ritmos distintos, la dimensión significante del conjunto para problematizar los alcances y límites de los diversos procesos y representaciones abordados.

Esta textualidad polifónica que al volver al pasado, lo incrusta en un presente y lo proyecta hacia un futuro, provoca que la indagación académica enriquezca sus miradas, que no ignore su condición paradójica, que renuncie a cualquier pretensión de conclusiones cerradas y que apele no solo a la racionalidad comprensiva del lector, sino también a una participación emocional y sensorial que lo movilice e interpele más raigalmente. Es posible pues afirmar que, desde la perspectiva de Procesos autónomos como investigación, estos recursos resultan muy apropiados para articular una mirada crítica que aborde la condición fallida de la nación peruana, las ambigüedades y contradicciones en procesos y actores que han apostado y apuestan por la autonomía, la persistencia (y reinterpretación) en el tiempo de los mismos lastres que atentan contra las utopías y deseos emancipatorios que se trizaron en el camino, y atienda a la vigencia (tenue) de estos mismos, 
que a pesar de su fracaso o abandono, no dejan de evidenciar restos que quisieran rearticularse, perspectiva que el propio poemario, a pesar del pathos desencantado que prima en él, parece representar.

Desde esta perspectiva, resulta oportuno profundizar en los procedimientos textuales de reescritura e indagar, en particular, en cómo los intertextos poéticos participan en la dinámica de la investigación. Recordemos que además de fragmentos de poesía popular (lírica popular limeña cantada) -que se proponen sobre todo como ejemplificaciones o contrapunto de lo que se va desarrollando en los poemas, o como banda sonora que ilustra lo que se problematiza-, aparecen en los poemas diversos fragmentos de la poesía "culta" (Cornejo Polar) canónica del Perú contemporáneo (Eielson, Cisneros, Hinostroza, Verástegui, Varela, Ollé, Santiváñez, entre otros), cuya articulación en los poemas es más compleja o menos transparente en cuanto a los sentidos que permiten establecer, pues no parecen ilustrar lo desarrollado, sino generar otro tipo de lecturas. Veamos un ejemplo en el poema sobre el cronista Borregán.

Se trata de una cita de Jorge Eduardo Eielson en la sección "[De Cajamarca al sitio del Jr. Cuzco]". Al incorporarse en el discurso del hablante del poema, los versos de Eielson contribuyen a la mirada crítica que se desarrolla. La cita, "y lo vertiginoso es un muchacho / completamente inmóvil (Eielson 1996; 51)", proviene de su poema "Azul ultramar" de Habitación en Roma (1952), y es el inicio de una frase que se completa, en un giro semántico respecto de su contexto original ${ }^{20}$, con los versos: “esperando en la entrada / la entrada de los tanques/ dispuesto a luchar / con un lápiz en la mano / como si se batiera un griego / adornado solo / con una lanza / contra doscientos soldados / mejor equipados: / balas de hule y / macanas / sus granadas recién cosechadas / sintiendo / el miedo enroscarse / y triturarle las costillas / un calor insoportable / anegando sus axilas / un solo muchacho / cubierto de gases / un cuadro forjado / al interior del partido / completamente inmóvil / esperando / el embate de los caballos / y dispuesto a morir" (43). La cita completa permite comprender algunos procedimientos de construcción discursiva en el libro. El verso de Eielson da forma inicial a un personaje cuya inmovilidad, visualmente captada en el poema, potencia, a través del procedimiento de

20 Que expresa la desolación de un sujeto ante la pérdida de los sentidos de sacralidad (profana) y comunidad de la experiencia humana en el contexto de una modernidad avasalladora, individualista y deshumanizante. 
montaje, la conjura de varios tiempos y territorios, que quedan así ligados para que el lector establezca las posibles relaciones entre ellos.

La variación en el título (de "De Cajamarca al sitio del Cuzco" en la crónica de Borregán a "[De Cajamarca al sitio de Jr. Cuzco]" 21 ), en cotejo con la escena del poema, nos acerca al presente y posiblemente a las calles del centro histórico de Lima (el Jr. Cuzco), en que un solo hombre (un "cuadro del partido") enfrenta valientemente a los tanques y soldados de las fuerzas del orden. La referencia a los tanques, en conjunción con la inmovilidad del muchacho, recuerda las fotografías de la plaza de Tiananmen, en China, en 1989, símbolo de la rebeldía y la entereza en la defensa de una causa libertaria. El anonimato del joven y su adscripción al partido sugiere que, como este, podrían haber sido otros "cuadros", lo que a su vez remite a los desencuentros referidos en diversos lugares del poemario entre dirigencia y bases, al abandono de la voluntad de lucha y adelgazamientos ideológicos abordados en la tercera parte del libro o a los contrastes entre militantes organizados y jóvenes diletantes. La imagen propuesta y la referencia a los "doscientos soldados" a los que enfrenta el muchacho, equiparado a "un griego", por su parte, remiten a la épica clásica (Aquiles o Heracles, quizá, frente a un número muy superior de enemigos), y aluden, además, por el lápiz mencionado, a la condición de estudiante del joven que combate también con ideas, argumentos y voluntad de saber; pero que se expone igualmente a ser violentado o torturado por las fuerzas del orden, con ensañamiento análogo, según sugiere otro salto temporal, al empleado con Túpac Amaru II, que no pudo ser descuartizado ni por la fuerza de cuatro caballos, como podría sugerirse al final del poema. Como se ve, la imagen del muchacho "completamente inmóvil" de Eielson posibilita la reverberación múltiple de la imagen y traza conexiones entre diversos momentos de la historia: fragmentos del pasado que relampaguean como "imágenes dialécticas" (Benjamin) en el presente de la enunciación, revelando no solo comprensiones nuevas, sino sentidos nuevos que inciden en el hoy. De modo semejante, la cita literal y las alusiones a otros poetas y poemas se engarzan con las complejas estrategias temporales en que momentos diversos (la conquista, la primera mitad del XX, el velasquismo, los años ochenta y el presente) se imbrican

21 Como en todo el poemario, los títulos prestados invitan a dar atención a los sutiles o más claros hilos conductores entre momentos diversos de la historia, lo mismo que entre registros y disciplinas distintas. 
en la escritura a partir de las imágenes fragmentarias del ahora-tiempo que interrumpen la linealidad (Rosman 19) de la historia, promoviendo una serie de relaciones por tejer; relaciones de donde el poema habrá de extraer las "ideas" centrales del proyecto de análisis y crítica social que lo anima, puesto que "sin ideas no hay poesía", dice Fernández en la sexta de sus conclusiones: "Sin ideas no hay nada que decir. Sin ideas el poema no va a ninguna parte y es necesario que los poemas vayan a alguna parte, tengan un objetivo, tracen una estrategia" (75).

Como esta, todas las conclusiones -que pueden leerse como arte poética del libro al declarar los fines y alcances, estéticos e ideológicos, del proyecto de escritura- sitúan a Procesos autónomos como un trabajo de mediación (entre la realidad factual y los hechos del lenguaje) que introduce en el poema lo que está fuera de él, para "someterlo a la escritura", pues "es claro que la escritura es un hecho inherente, indesligable y suficiente para el poema". La poesía, por ello, "es solo lo que acaece en el poema" (75), pero a partir de dicho proceso de mediación. Entender esta poética permite abordar los lenguajes y códigos de las ciencias sociales presentes en el libro como lenguajes de la poesía, a la vez que reconocer en todo esto el proyecto de Fernández (iniciado con Octubre, de 2006) de asumir la responsabilidad ética de mirar la compleja diversidad del país desde un universo verbal igualmente diverso, complejo y plural.

La responsabilidad ética y política de la poesía fue un componente habitual de la comprensión de lo poético del paradigma conversacional consolidado en el continente y en Perú en los años sesenta del siglo pasado (Cornejo Polar, Fernández Retamar, Fischer). Esta perspectiva -que, como señala Gustavo Guerrero, constituyó uno de los últimos hitos del "sistema moderno" fundado con el Romanticismo, el cual sostenía el "superior alcance cognitivo de la poesía" (22) - comienza a derrumbarse hacia los años ochenta, y su crisis y final, en correlación con el asentamiento de los discursos acerca de la posmodernidad y la consolidación del modelo neoliberal en el continente (Rowe, Cárcamo y Mazzotti), corroen en general la confianza en las posibilidades de la poesía de aportar de algún modo a la transformación de la sociedad. En el caso peruano, en los noventa claramente se acaba la "hegemonía de lo conversacional" (Chueca 2009) que había regido por más de dos décadas, y la mayor parte de los poetas jóvenes que comienzan a publicar en esos años descartan de sus registros poéticos las referencias, alusiones e incluso preocupaciones explícitamente políticas. Así ocurre hasta mediados de la primera década de los 2000, en que estas vuelven a aparecer, 
sobre todo vinculadas con los trabajos de la memoria (Jelin) respecto del proceso de violencia política de finales del XX (Villacorta, Chueca 2017). En este contexto, puede considerarse a Procesos autónomos como un trabajo poético que contribuye a la revitalización de las posibilidades y alcances del paradigma conversacional, aunque quizá no imaginando una contribución a la transformación social, pero sí acicateando un mirar crítico desde la poesía.

\section{PARA CONCLUIR}

Desde los registros y posibilidades de la poesía, el autor establece un diálogo complejo entre compromiso ético y voluntad política, indagando en las dinámicas de configuración de proyectos autónomos en la sociedad peruana por medio de las discusiones sobre las imágenes del país, de las que este libro participa, a partir de la consideración del poema no solo como artefacto verbal, sino también como evento social de inevitable mundaneidad (Said). En este sentido, en Procesos autónomos, los lenguajes de las ciencias sociales y la poesía se conciben como construcciones discursivas, cuya narrativa se elabora desde una determinada perspectiva cultural e ideológica, con base en hechos registrados o documentados en diversas fuentes: textos de historia, antropología, poesía, crítica social y cultural, archivos, testimonios, material fonográfico, entre otras. Lo que implica que el carácter documental de los poemas está dado por la textualización o poetización del material utilizado como fuente o modelo para el ejercicio reescritural (citas, alusiones, epígrafes, notas al pie de página, referencias bibliográficas, etc.), del que depende la mirada deconstructiva y crítica hacia la proyectos de autonomía en el Perú.

Frente a sus fuentes y materiales de trabajo y estudio, el poeta no es imparcial, antes bien, él adopta el punto de vista de un sujeto implicado con su objeto de estudio, que participa, delibera y sopesa respecto de aquél. Por lo que los registros y formatos utilizados en el proceso de reescritura (lírico, épico, informativo, narrativo; verso, prosa, visualidad; nota al pie, relato oral, diario personal, etc.) no solo evidencian un replanteamiento constante del lenguaje de acuerdo con las necesidades expresivas, sino que ellos suponen, además, un radical desafío de las concepciones estrechas acerca de lo que puede ser o no poesía, para proponer, desde ahí, el poemario como un intenso campo de trabajo e investigación en el ámbito de la palabra poética en relación con el mundo y con la necesidad de recuperación de su capacidad movilizadora. 
De acuerdo con lo anterior, Fernández examina ciertos periodos y hechos de la historia del Perú, enfatizando, desde documentos y fuentes bibliográficas diversas, algunos proyectos políticos de construcción de la nación peruana durante el siglo XX. El poeta-investigador tiende a borrar o a confundir los límites entre poesía y ciencias sociales, en una imbricación de lenguajes y saberes que aproximan (y abisman) el texto poético hacia una "literatura fuera de sí" (Garramuño) que transgrede las fronteras del contenido específico disciplinario o artístico para dialogar de un modo complejo con elementos propios de otras disciplinas o campos del saber. Se podría señalar, en ese sentido, que en Procesos autónomos se entrelazan perspectivas posmodernas que responden a la productividad de lo híbrido -interdisciplinario o interartístico-, para destacar las fracturas, las múltiples violencias y las derrotas de los proyectos de sociedad más valiosos, también los vacíos, asimetrías y jerarquizaciones, identidades heterogéneas y dinámicas multitemporales y multiespaciales surgidas de la diversidad de las matrices que conforman el país, así como de las relaciones con el entorno internacional y la globalización. El poemario plantea preguntas respecto de todo ello, dejando clara la incertidumbre o la ausencia de una respuesta totalizadora, única o final. Pero es esa misma incertidumbre la que permite entender lo nacional como una narración cambiante que resulta de permanentes contiendas y reacomodos discursivos y políticos.

\section{BIBLIOGRAFÍA}

Benjamin, Walter. Iluminaciones. Madrid: Taurus, 2018.

Borregán, Alonso. Crónica de la Conquista del Perú. Edición de Rafael Loredo. Sevilla: Escuela de Estudios Hispano-Americanos, 1948 [1565].

Buntinx, Gustavo. "Entre lo popular y lo moderno. Alternativas pretendidas o reales en la joven plástica peruana". Hueso Húmero 18 (1983): 61-85.

Cárcamo-Huechante, Luis y José Antonio Mazzotti. "Dislocamientos de la poesía latinoamericana en la escena global". Revista de Crítica Literaria Latinoamericana 58 (2003): 9-21.

Chueca, Luis Fernando. "¿La hegemonía de lo conversacional? Notas para continuar una discusión”. Intermezzo Tropical 6-7 (2009): 134-140.

"Poesía y violencia política en los poetas de los años noventa en el Perú (revisión panorámica y estudio del caso de Ya nadie incendia el mundo, de Victoria Guerrero)". En Lineas Generales 1, 2017. 71-83. https://revistas.ulima.edu.pe/index.php/enlineasgenerales/ article/view/1832/1861 
Cornejo Polar, Antonio. "La problematización del sujeto en la poesía conversacional". Homenaje a Alfredo Roggiano: en este aire de América. Eds. Keith McDuffie y Rose S. Minc. Pittsburgh: University of Pittsburg e Instituto Internacional de Literatura Iberoamericana, 1980. 201-207.

La formación de la tradición literaria en el Perú. Lima: CEP, 1989.

Escribir en el aire. Ensayo sobre la heterogeneidad socio-cultural en las literaturas andinas. Lima: Horizonte, 1994.

Cotler, Julio. Clases, estado y nación en el Perú. Lima: IEP, 1986.

Didi-Huberman, Georges. Cuando las imágenes toman posición. Madrid: Antonio Machado Libros, 2008.

Eielson, Jorge Eduardo. Poesía escrita. Lima: Instituto Nacional de Cultura, 1976.

Fernández, Manuel. Octubre. Lima: Estuendomudo, 2006.

La marcha del polen. Lima: Estuendomudo, 2013.

Procesos autónomos. Lima: Estruendomudo, 2016.

Fernández Retamar, Roberto. “Antipoesía y poesía conversacional en Hispanoamérica”. Para una teoría de la literatura hispanoamericana y otras aproximaciones. La Habana: Casa de las Américas, 1975. 111-126.

Fischer, María Luisa. "Introducción”. Historia y texto poético. La poesía de Antonio Cisneros, José E. Pacheco y Enrique Lihn. Concepción: Lar, 1998.

Galeano, Eduardo. Las venas abiertas de América Latina. Buenos Aires: Siglo XXI, 1975.

Garramuño, Florencia. La experiencia opaca. Literatura y desencanto. Buenos Aires: FCE, 2009.

Gonzales, Osmar. Señales sin respuesta. Los zorros y el pensamiento socialista en el Perú 1968-1989. Lima: PREAL, 1999.

Guerrero, Gustavo. Cuerpo plural. Antología de la poesía hispanoamericana contemporánea. Valencia: Pre-Textos, 2010.

Hernández, Biviana. "La reescritura como estilización paródica en Facsímil de Alejandro Zambra y Curriculum vitae de Rodrigo Lira”. Estudios Filológicos 63 (2019): 99-119.

"Notas para una poética de apropiación: Donde comienza el aire de Soledad Fariña". Acta literaria 57 (2018): 93-118.

Jelin, Elizabeth. Los trabajos de la memoria. Lima: Instituto de Estudios Peruanos, 2012.

Lowy, Michael. Walter Benjamin, Aviso de incendio. Buenos Aires: FCE, 2005.

Macera, Pablo. Visión histórica del Perú. Del Paleolítico al proceso de 1968. Lima: Milla Batres, 1978.

Masiello, Francine. El cuerpo de la voz. (Poesía, ética y cultura). Rosario: Beatriz Viterbo y Universidad Nacional de Rosario, 2013.

Meléndez, Carlos. "Mediaciones y conflictos: las transformaciones de la intermediación política y los estallidos de violencia en el Perú actual". Víctor Vich (ed.). El Estado está de vuelta: desigualdad, diversidad y democracia. Lima: IEP, 2005. 159-183.

Montalbetti, Mario. Notas para un seminario sobre Foucault. Lima: FCE, 2018. 
Oliva, Carlos. Lima o el largo camino de la desesperación. Lima: Hispano Latinoamericana, 1995.

Ollé, Carmen. Noches de adrenalina. Lima: Cuadernos del Hipocampo, 1981.

Pound, Ezra. Personae. Traducción de Ricardo Silva Santisteban. Lima: Pedernal, 1995.

Quijano, Aníbal. “Colonialidad del poder, eurocentrismo y América Latina”. Edgardo Lander, comp. La colonialidad del saber. Eurocentrismo y ciencias sociales. Perspectivas latinoamericanas. Buenos Aires: CLACSO, 2000. 201-246.

Rohner, Fred. "Fuentes para el estudio de la lírica popular limeña: el repertorio de Montes y Manrique". Lexis XXXI. 1 (2007): 331-355.

Rosman, Silvia. Dislocaciones culturales: nación, sujeto y comunidad en América Latina. Rosario: Beatriz Viterbo Editora, 2003.

Rowe, William. Hacia una poética radical: Ensayos de hermenéutica cultural. México D.F.: FCE, 2014.

Said, Edward W. El mundo, el texto, el crítico. Buenos Aires: Debate, 2004.

Sánchez Flores, Miguel. "Más allá del pop achorado: una propuesta de relectura de los afiches de Jesús Ruiz Durand para la Reforma Agraria del gobierno de Juan Velasco Alvarado". Tesis de Magíster en Historia del Arte y Curaduría. Lima: PUCP, 2016.

Villacorta, Carlos. "La reconstrucción de la memoria: la poesía peruana después de la violencia política 2000-2010”. Letras 87. 125 (2010): 123-134.

Zariquiey, Roberto. Tratado de arqueología peruana. Lima: PUCP, 2005.

Žižek, Slavoj. "La política de la verdad o Alain Badiou como lector de San Pablo". El espinoso sujeto. El centro ausente de la ontología política. Buenos Aires: Paidós, 2001. 137-181. Acontecimiento. Madrid: Sexto Piso, 2015. 